\title{
FINE STRUCTURE OF SPERMIOGENESIS IN THE TICK AMBLYOMMA HEBRAEUM (ACARI: IXODIDAE): LATE STAGES OF DIFFERENTIATION AND STRUCTURE OF THE MATURE SPERMATOZOON ${ }^{1}$
}

\author{
Ashraf El Said,, ${ }^{2,3}$ Zdzislaw Swiderski, ${ }^{2}$ Andre Aeschlimann ${ }^{4}$ and Peter A. Diehl ${ }^{4}$
}

\begin{abstract}
Spermatids of Amblyomma hebraeum were examined by light and electron microscopy. These large, elongate, tubular cells are pointed at one end and truncate at the other. Each is composed of an outer sheath and an inner cord. The outer sheath lining and the inner cord surface are composed of cellular processes joined at the truncate end of the sperm cell. The nucleus is in the outer sheath. The semispherical apex of the inner cord is covered by numerous bulbous expansions. The final stage of spermiogenesis is the simultaneous evagination of the inner cord at the pointed end and invagination of the outer sheath at the truncate end of the cell. The mature spermatozoon, ca. $200 \mu \mathrm{m}$ long and consisting of the inner cord added to the former outer sheath, is clavate anteriorly and caudate posteriorly, where the nucleus is located. The mature spermatozoon contains $\beta$-glycogen particles and large peripheral granules. A prominent acrosomal complex associated with the nucleus is observed in the aging spermatozoon. The cellular processes and/or the fibrillar granular cytoplasm may have a role in sperm movement.
\end{abstract}

Tick spermatogenesis has been described by Bonnet (1907), Samson (1909), Casteel (1917), Warren (1933), Oppermann (1935), Tuzet \& Millot (1937), Sharma (1944), Wagner-Jevseenko (1958), Till (1961) and Khalil (1969, 1970). Other investigations using electron microscopy were conducted by Rothschild (1961), Reger (1961, 1962, 1963, 1974), Breucker \& Horstmann (1968, 1972), Feldman-Muhsam \& Filshie (1974, 1976, 1979), Feldman-Muhsam et al. (1975), Wüest et al. (1978), and El Said \& Swiderski (1980a, b, c).

The present study was undertaken to determine the ultrastructure of the differentiating spermatids and mature spermatozoa in Amblyomma hebraeum Koch (Ixodidae) and to compare our results with those reported for other tick species. Spermato-

\footnotetext{
1 This investigation was supported in part by Grant 3.916.72 from the Swiss National Science Foundation. Request reprints from Dr. Z. Swiderski at the University of Geneva.

2 Department of Animal Biology, Laboratory of Comparative Anatomy and Physiology, University of Geneva, CH-1211 Geneva 4, Switzerland.

${ }^{3}$ Present address: Embassy of the Arab Republic of Egypt, The Hague, The Netherlands.

${ }^{4}$ Institute of Zoology, University of Neuchatel, CH-2000 Neuchatel, Switzerland.
}

genesis and sperm maturation in $A$. hebraeum have not previously been studied by light or electron microscopy.

\section{MATERIALS AND METHODS}

Unfed adult $A$. hebraeum (kindly supplied by Les Barges Research Unit, Ciba-Geigy, Vouvry, Switzerland) were placed for feeding in metal capsules fixed to the backs of laboratory rabbits.

Copulation was sometimes observed in the laboratory when engorged males and partly engorged females were placed together in a petri dish shielded from light by a black cloth and warmed by a lamp (El Said et al., data in prep.). As soon as the ticks assumed the mating position, they were observed for the rest of the process under a binocular microscope.

To study the spermatid and the elongation process, the mating process was interrupted after formation of the sperm-containing spermatophore, which was removed from the male genital orifice before reaching the female.

To study mature spermatozoa, females that had mated and engorged were dissected in physiological saline for light microscopy or in $0.1 \mathrm{M}$ cacodylate buffer ( $\mathrm{pH}$ 7.4) for electron microscopy.

Endospermatophores containing spermatozoa were dissected free from the female seminal receptacles. Both ecto- and endospermatophores were immediately pierced with a fine pin to facilitate penetration of fixatives and embedding media.

Mitochondrial distribution was studied in fresh tissue stained with $0.2 \%$ Janus green $B$. For in vivo observations, phase contrast microscopy was sometimes used. For electron microscopy, freshly dissected tissue was prefixed in $4 \%$ glutaraldehyde in $0.1 M$ cacodylate buffer at $\mathrm{pH} 7.4$ for at least 24 $h$. The material was then washed in 2 or 3 changes of the same buffer for $24 \mathrm{~h}$. Postfixation was carried out in cold $2 \% \mathrm{OsO}_{4}$ for $1 \mathrm{~h}$; material was then dehydrated in successive grades of ethanol 


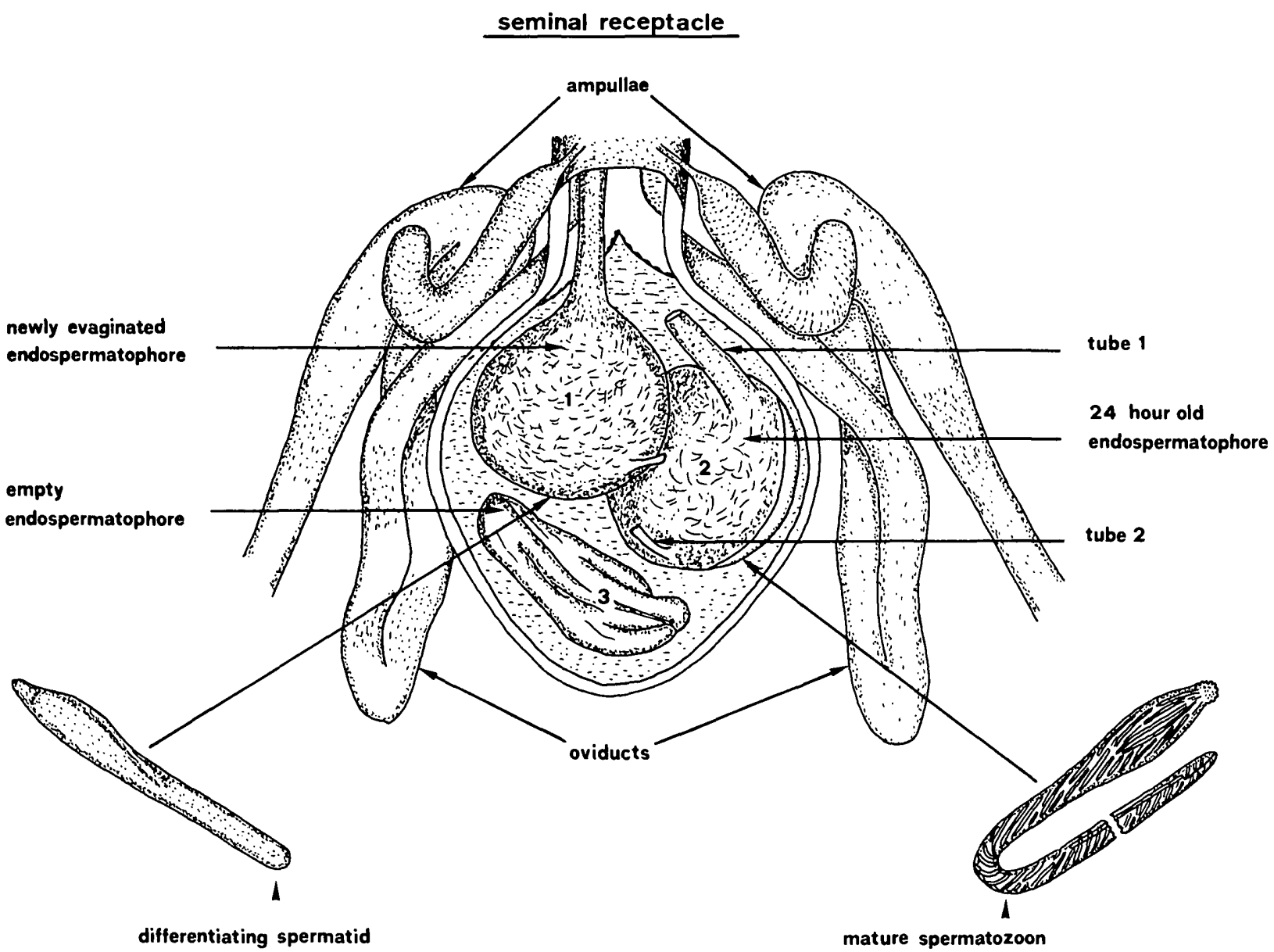

Fic. 1. Schematic diagram of the seminal receptacle of mated $q$ containing endospermatophores of different ages. Note the differentiating spermatid in the newly evaginated endospermatophore and the mature spermatozoon in the 24-h-old endospermatophore.

and, after 2 changes of propylene oxide, embedded in Spurr or Durcupan ACM Fluka. Fine and semifine sections were cut with glass knives on a Reichert ultra microtome. Fine sections were stained with uranyl acetate (Watson) and lead citrate (Reynolds) and examined with a Hitachi HS $7 \mathrm{~S}$ electron microscope.

To demonstrate glycogen, the periodic acidthiocarbohydrazide silver proteinate method of Thiery (1967) was used.

\section{RESULTS}

During copulation, an ectospermatophore ejected from the male genital orifice contains an endospermatophore into which seminal fluid and sperm cells are injected. This endospermatophore evaginates in the female genital tract where the contents of the ectospermatophore are released.
One to 5 endospermatophores may be found in the seminal receptacle of mated females.

Sperm cells in the newly evaginated endospermatophore are still immature. These spermatids elongate and develop into mature spermatozoa in 1-2 days (Fig. 1). The mature spermatozoa leave the endospermatophore about 2 days later, migrate up the oviducts and accumulate in great numbers in the ampulla region.

\section{Fine structure of the spermatid}

The main body of the spermatid (Fig. 2-15) is composed of 2 long tubes: the outer sheath and the inner cord, the former surrounding the latter. Both tubes are connected at the posterior truncate end of the spermatid (Fig. 2, 6, 11a). The anterior end (Fig. 11a) is slightly broader, with its apex acutely tapering. The outer sheath and inner cord 
are separated by the cisternal cavity (Fig. 2) containing a granular material.

The rod-shaped, electron-dense nucleus extends for about $1 / 2$ the anterior length of the spermatid (Fig. 11a). When observed in vivo, the nucleus is easily seen lying over the layer of cellular processes beneath the membrane of the outer sheath and distending the sperm surface (Fig. 2, $11 \mathrm{~b}, \mathrm{c}$ ).

A semispherical structure of unknown function, entirely covered by numerous regular rows of bulbous expansions, lies at the anterior tip of the inner cord (Fig. 2-4). In the midregion of this semisphere, the last row of bulbous expansions extend as a fringe of motile processes (Fig. 2, point 5). At the anterior end of the spermatid, the acrosome underlies the cellular membrane.

In the anterior part of the spermatid, the moderately dense granular cisternal cavity contains several small vesicles (Fig. 2, point 1). The cytoplasm of the middle and posterior parts is fibrillar-granular (Fig. 5, 6). The granules may represent fibers in cross section. Both fibrillar and granular elements measure about $100-150 \AA$ in diam.

The fibrillar-granular cytoplasm in the middle and distal part of the cell accumulates as dense clusters bordering the inner surface of the inner tube (Fig. 2, points 7-9). In this cortical region, there are also numerous dense fibers, appearing in longitudinal sections to extend the length of the spermatid.

The cellular processes extend from the foot of the semispherical structure for the length of the spermatid and cover the entire surface of the inner cord to the posterior apex of the cell. At the point of fusion of inner cord and outer sheath, these processes fold externally upon themselves and extend to the pointed end of the spermatid (Fig. 2, 6, 11). Externally, the cellular processes curve around the sperm surface (Fig. 12); they are equidistant and essentially parallel (Fig. 8,9) and most begin immediately following the termination of another (Fig. 9, arrows). Where certain terminating processes do not follow another, flanking processes draw closer and are ultimately parallel (Fig. 12 , arrows). Each cellular process is attached to the cell membrane by a short stalk (Fig. 15).

Cellular processes seen in cross section are arranged in 2 concentric circles inside the cisternal cavity (Fig. 7, 10), 1 in the outer sheath and 1 in the inner cord (Fig. 11a). Each process is pyriform in cross section and composed of 3 subunits of varying electron density (Fig. 10). The 1st (a) is homogeneous and of relatively low density. The 2nd (b) is crescentic and darkly staining; it overlaps type a at the broad end of the pyriform process. The small, filamentous 3rd form (c) usually represents a terminating end of the process.

\section{Elongation}

Final development of the spermatozoon is completed in the endospermatophores within the seminal receptacle of mated females and requires at least $24 \mathrm{~h}$ (Fig. 1).

An operculum (Borut \& Feldman-Muhsam 1976, Wüest et al. 1978) detaches from the pointed tip of the spermatid (Fig. 11a) during the forward movement of the conical apex of the inner cord. The freed conical apex bulges (Fig. 1lb) and the outer sheath carrying the nucleus slips posteriorly to invaginate at the truncate end of the elongating spermatid (Fig. 11b, c). A fold in the freed bulge of the inner cord folds out and swells, forming the eventual clavate anterior part of the mature spermatozoon (Fig. 11b, c).

The anterior bulge results from the outward expansion of the longitudinal fold seen in cross sections of the immature spermatid (Fig. 7, 10). Evagination and invagination occur simultaneously and continue until the outer sheath and the inner cord merge. Thus, a single clavate structure, double the length of the original spermatid, is formed.

\section{The mature spermatozoon}

The mature spermatozoon remains in the endospermatophore within the seminal receptacle for 3-4 days, then migrates up the oviducts to the ampulla and very rarely to the ovaries.

The mature spermatozoon is composed mainly of the anterior region of the former inner cord added to the former outer sheath that has turned inside out (Fig. 12).

The internal structure of the spermatozoon is similar to the inner cord of the spermatid, thus only differences observed between both stages will be mentioned.

The final external features of the mature spermatozoon are characterized by a thick clavate anterior end carrying a semispherical apical structure covered by numerous small expansions. A short fringe of motile processes encircles the apical structure just posterior to the bulbous expansion (Fig. 12).

Upon completing spermiogenesis, the clavate anterior end flattens and the posterior part forms a long, thin "caudal" region.

As a result of invagination of the outer sheath, 


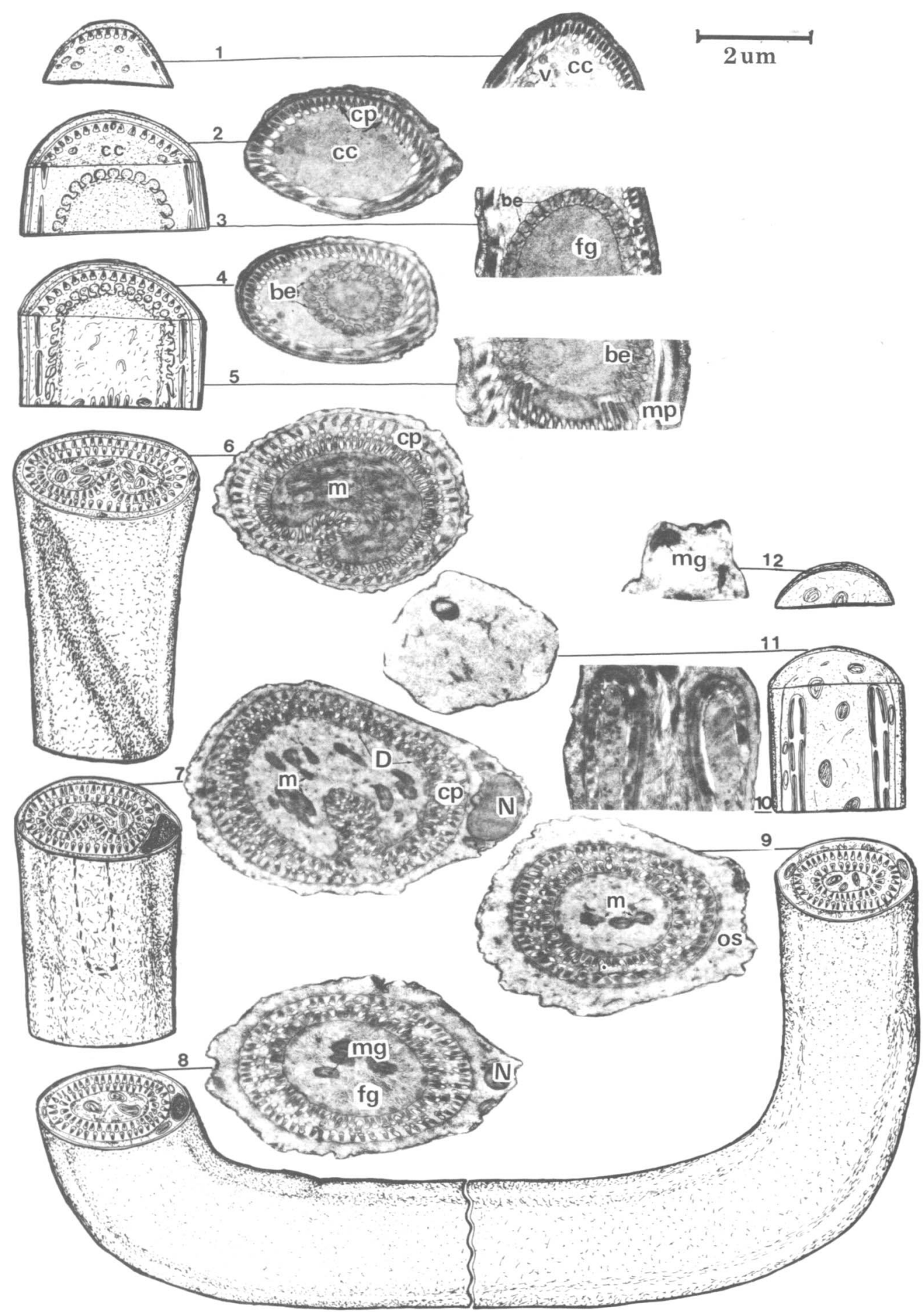

Fic. 2. Three-dimensional reconstruction of the spermatid with micrographs of the corresponding cross and longitudinal sections through different regions. Note the cellular processes (cp) of the outer sheath (OS) encircling the bulbous expansions (be) at the tip of the inner cord, followed by motile processes $(\mathrm{mp})$ and cellular processes (cp) inside the cisternal cavity (cc). The fibrillar-granular region (fg) at the anterior part is denser than in the posterior nucleate region $(\mathrm{N})$. The cytoplasm contains numerous mitochondria $(\mathrm{m})$, and dense fibers (D). Several vesicles (v) are observed in the cisternal cavity $(\mathrm{cc})$. 


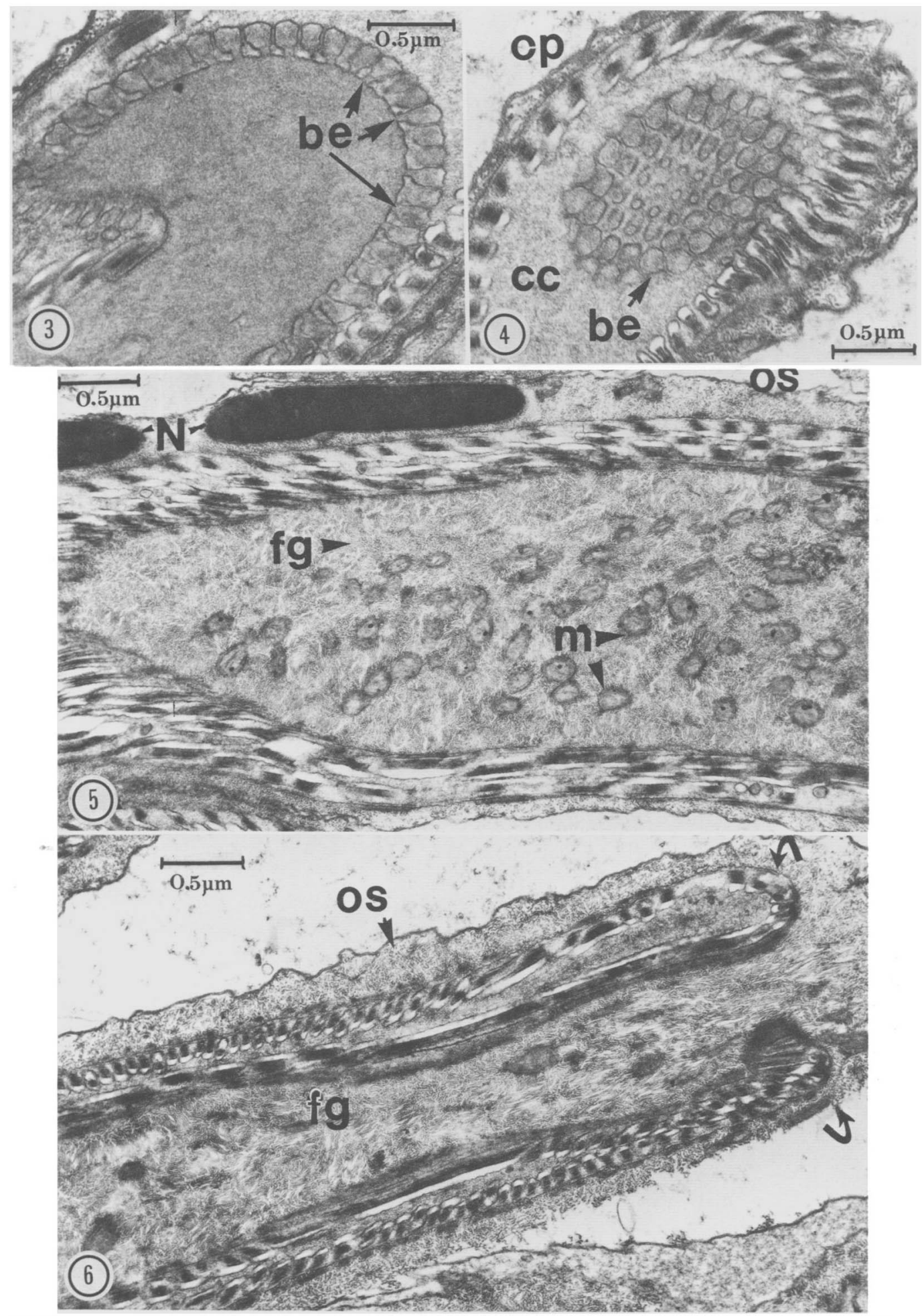

Fig. 3-6. 3, Longitudinal section through the bulbous expansions (be) connected by short stalks to the tip of the inner cord; 4, Cross section through the conical tip apex showing linear arrangement of bulbous expansions (be) inside the cisternal cavity (cc); 5, Longitudinal section through the nucleate part of the spermatid. Note the electron-dense nucleus $(\mathrm{N})$ in the outer sheath, mitochondria $(\mathrm{m})$, and fibrillar-granular cytoplasm of inner cord; 6, Posterior region of the spermatid representing point of attachment (arrows) of inner cord and outer sheath (OS). 

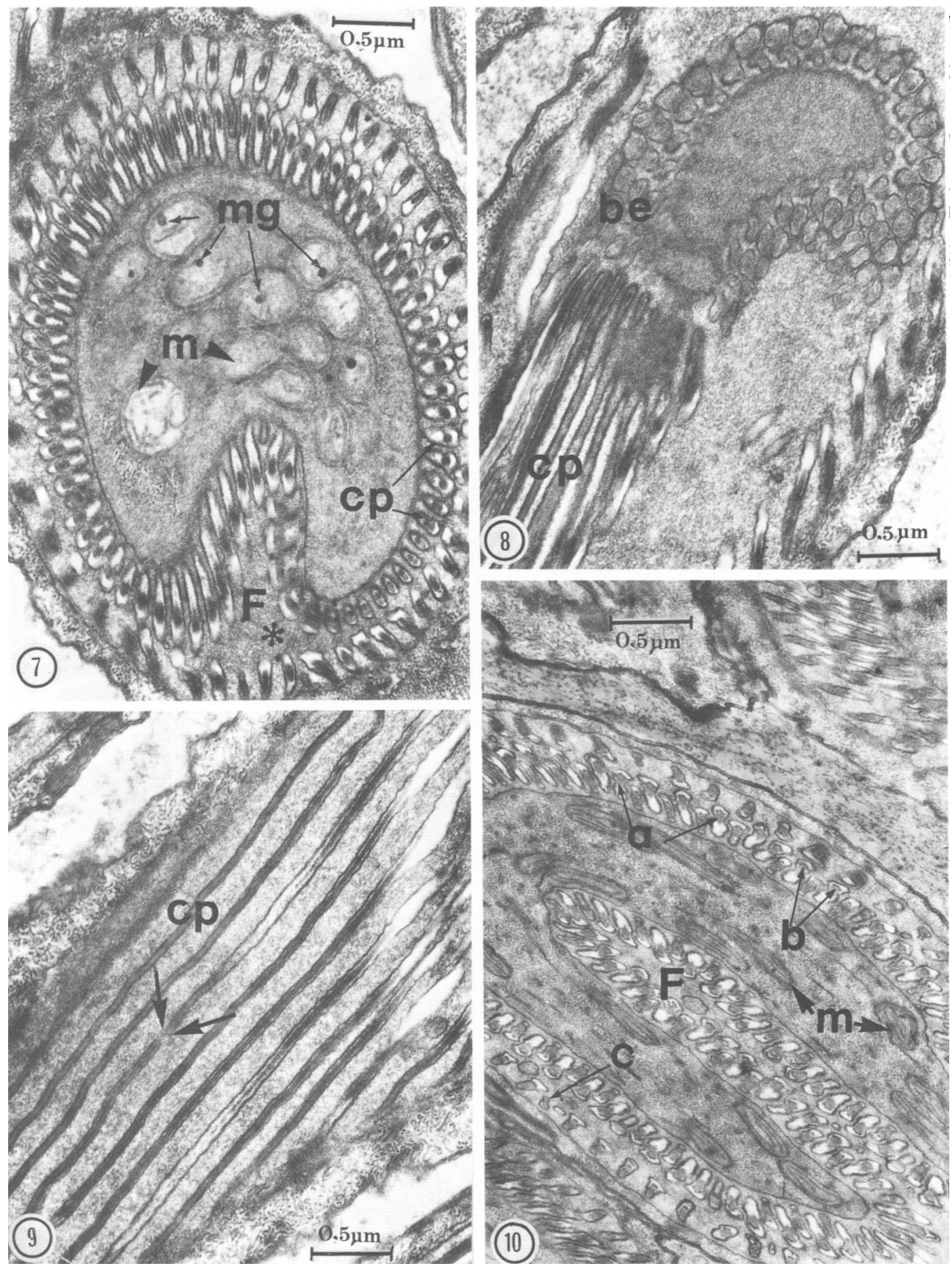

Fic. 7-10. 7, Cross section of spermatid showing accumulation of mitochondria ( $\mathrm{m})$ containing large electrondense mitochondrial granules $(\mathrm{mg})$. Note the fold $(F)$ in the inner cord and the 2 concentric circles of cellular processes (cp) inside the cisternal cavity $(*) ; 8$, Longitudinal section of the anterior part of spermatid showing the origin of the cellular processes (cp) at the base of the bulbous expansions (be); 9 , Tangential section of cellular processes (cp), showing arrangement, internal structure, and terminal points (arrows); 10, Cross section through anterior region of the spermatid showing the deep fold containing numerous elongated mitochondria (m). Note 3 following components of the cellular processes: (a) a homogeneous moderately dense part, (b) an electrondense crescentic part, and (c) a dwarfed terminal part. 

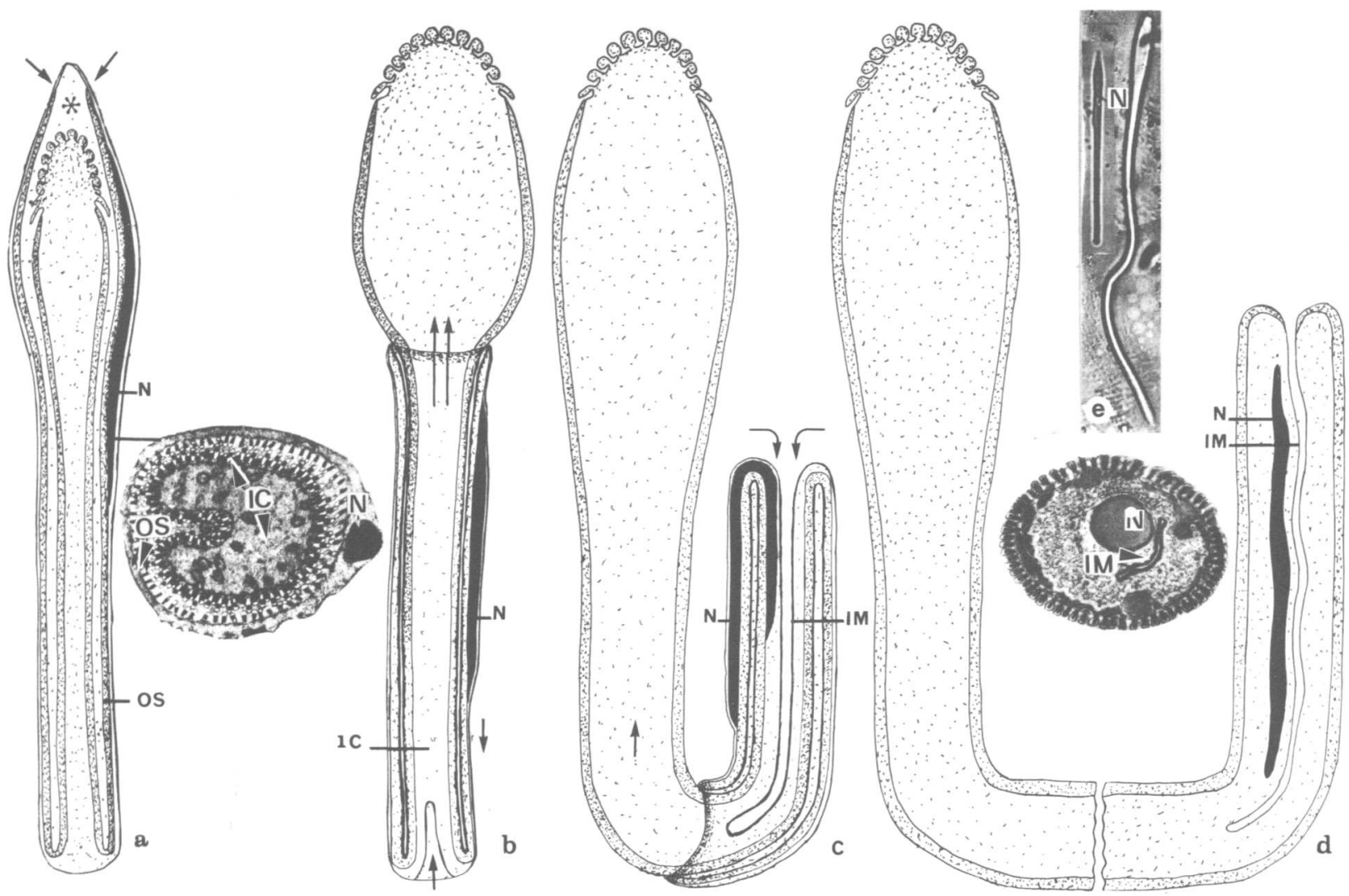

Fig. 11. Schematic diagram of the elongation process of the spermatid: a, Arrows show the point of detachment of the outer sheath (OS). Nucleus (N) is present in outer sheath (OS) at anterior end of spermatid. The inner cord (IC) is internal. Cisternal cavity $(*)$; $\mathbf{b}$, The evagination of the inner cord tip (arrows) and the evagination of the outer sheath (OS) at the truncate end; c, The evagination-invagination process. Note the migration of the nucleus (N) within the outer sheath (OS) into the sperm body; $\mathbf{d}$, The mature spermatozoon after completing elongation process. Note the bulbous head of the sperm and the inner and posterior position of the nucleus; e, Micrograph of spermatid before the elongation process and the mature spermatozoon.

the acrosome and nucleus are finally located in the "caudal" end of the sperm closely adjacent to the invaginated cell membrane (=invagination membrane), which lines the acrosomal canal (Fig. 11, 12 ). In young spermatozoa, the acrosome is represented by a thin, flattened vesicle, which is limited by a membrane; only a very narrow cytoplasmic zone separates the cell membrane from the acrosomal membrane. As the spermatozoon ages, this structure develops and its association with the nucleus is easily observed. The schematic diagram (Fig. 13) illustrates the acrosomal region and the nucleo-acrosomal association. An acrosomal plate (Fig. 14) becomes evident and is characterized as a moderately dense thickening of the acrosome. The plate extends for a short distance below and above its point of attachment with the nucleus; it is continuous with the acrosome (Fig. 13, 15). The base of the nucleus joins the nucleus to the acrosomal plate. A long, thin, moderately dense rod embedded in the nucleus and extending into it for a short distance apparently functions to strengthen the nucleo-acrosomal liaison by further fixing the acrosomal plate to the base of the nucleus. The nuclear membrane is always present.

The cell membrane (=invagination membrane) and the acrosome line a canal (=acrosomal canal) created by the invagination of the outer sheath during the elongation process (Fig. 11-15). Numerous tubular vesicles are seen accumulating within the acrosomal canal (Fig. 13).

The external surface of the mature spermatozoon appears ridged owing to cellular processes winding slightly in more or less parallel rows over the entire surface of the mature sperm.

The dense fibers observed in the inner cord of the spermatid appear now in the cortical region of the cytoplasm, usually underlying the spermatozoon plasma membrane.

Large peripheral granules are located extracel- 


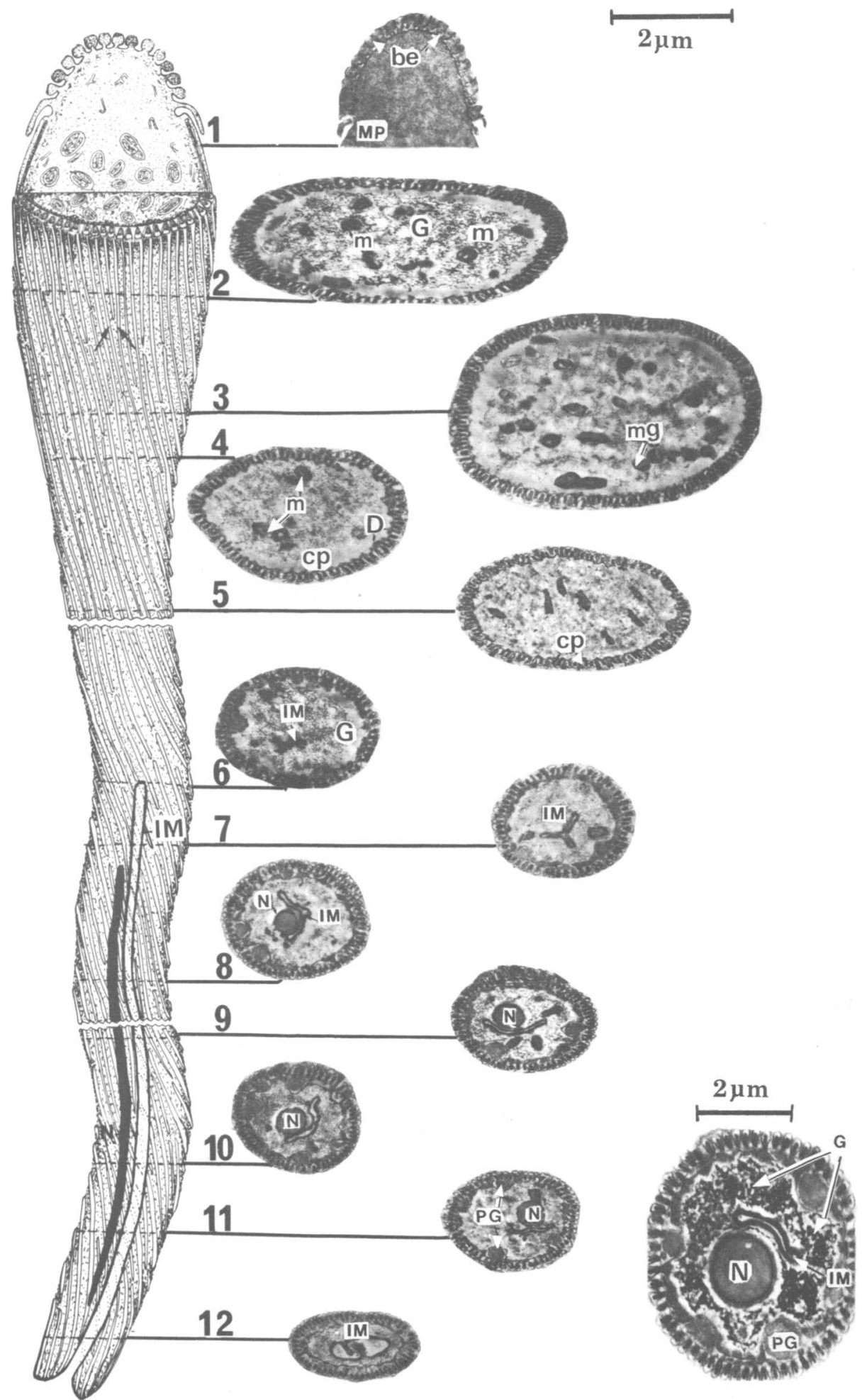

FIG. 12. Three-dimensional reconstruction of the spermatozoon with corresponding micrographs of different regions. Note the glycogen granules $(\mathrm{G})$ and mitochondria $(\mathrm{m})$ at anterior end, as well as the cell membrane $(\mathrm{cm})$ and underlying acrosome, nucleus $(\mathrm{N})$, glycogen $(\mathrm{G})$, and peripheral granules $(\mathrm{PG})$ at the posterior end. Inset: Cross section through nuclear part of spermatozoon demonstrating $\beta$-glycogen particles stained by the periodic acid-thiosemicarbazide-proteinate silver technique of Thiery (1967). 


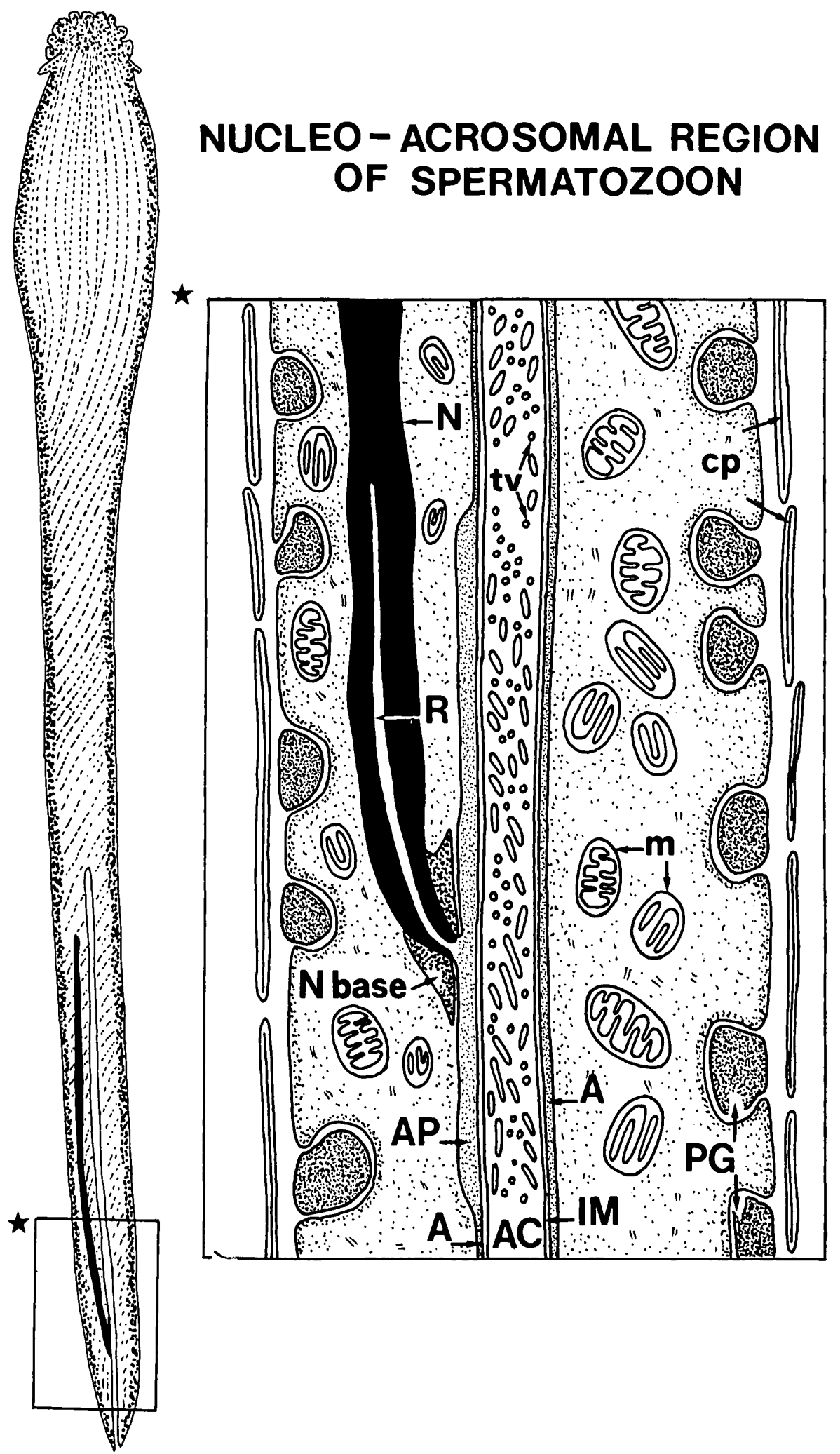

Fic. 13. Nucleo-acrosomal region of the spermatozoon (arrows indicate localization within the mature sperm). The acrosomal plate (AP) and the nucleus (N) are connected at the nuclear base ( $N$ base) by a long rod (R) centrally placed in the nucleus. The cell membrane (IM) and the acrosome (A) line the acrosomal canal (AC) in which numerous tubular vesicles (tv) are situated. cp: cellular processes. 

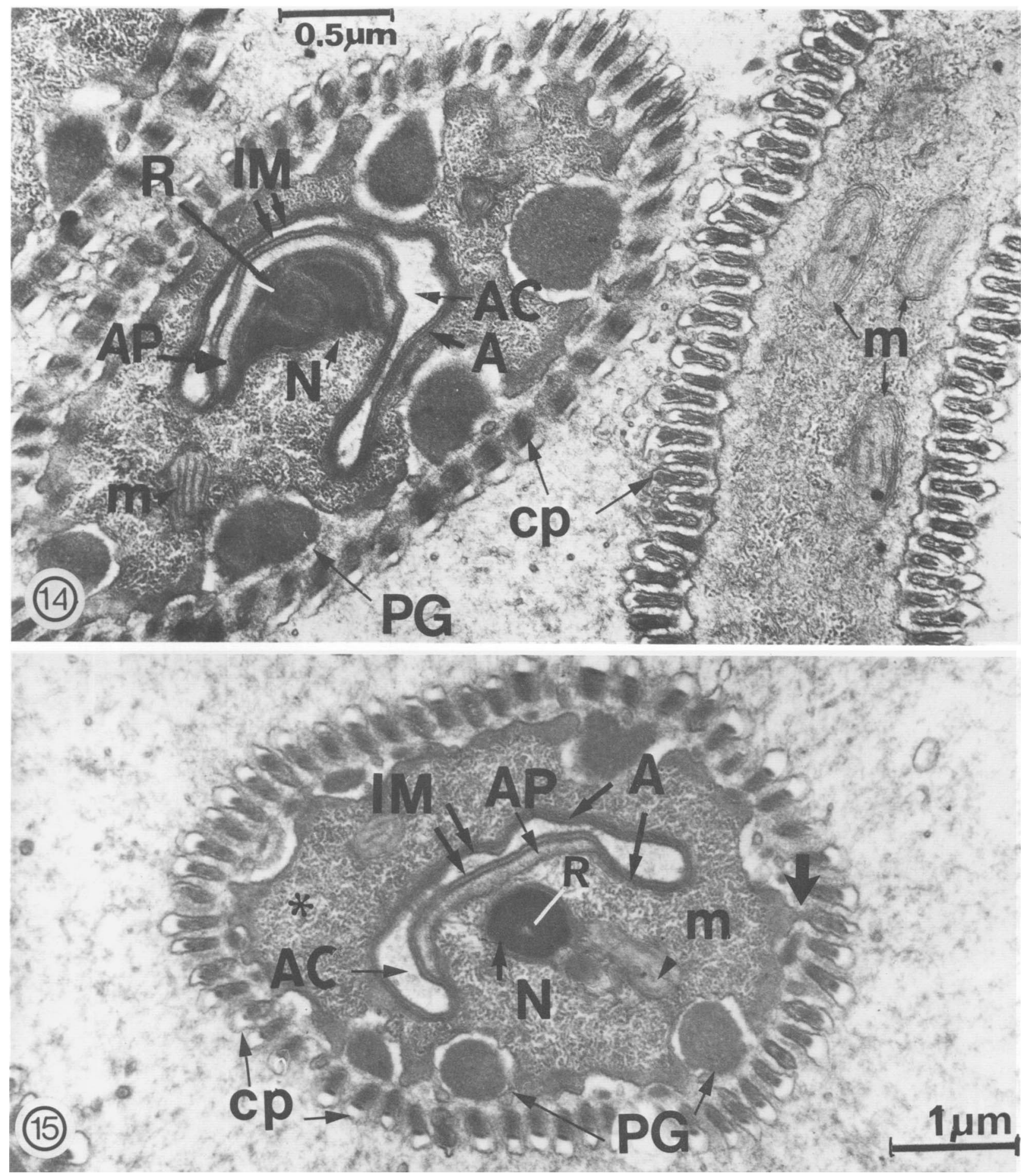

FIG. 14-15. 14, PG: peripheral granules. Site of acrosomal plate (AP) attachment with nucleus (N) and acrosomal canal $(A C)$. A: acrosome. The moderately electron-dense rod $(R)$ connects the acrosomal plate (AP) to the nucleus $(N)$ base. Peripheral granules (PG) become prominent at this stage and the electron lucent space separating them from the sperm cell membrane becomes more evident; 15 , The cell membrane (=invagination membrane IM), acrosomal plate (AP) and acrosome (A) at the "caudal" end of spermatozoon. Prominent peripheral granules $(\mathrm{PG})$, fibrillar-granular cytoplasm $(\mathrm{fg})$, and a single layer of cellular processes $(\mathrm{cp})$ are shown. A short stalk connects a cellular process to the sperm cell membrane $(\longrightarrow)$. 
lularly between the cellular processes and the plasma membrane, which separates them from the cortical cytoplasm. In older spermatozoa found in the oviducts and ampulla, these granules become more dense and appear to have a granular matrix (Fig. $14)$. Glycogen, represented by individual $\beta$-glycogen particles, is located in the central region of the spermatozoon (Fig. 12 inset).

\section{Motility}

Sperm movement was examined in fresh squash preparations under phase contrast. The sperm was seen to move with the clavate mitochondrial region followed by the thin nucleate "caudal" part. The fascinating sperm movement is a glide, usually in a straight line or occasionally in a rotating movement. When the sperm meets an obstacle, it surmounts it or turns away from large objects. The bulbous expansions on the conical apex and the surrounding circlet of motile processes are seen on close observation to be in continuous motion. A peculiar rolling-up and folding-out motion of the tip of the flattened anterior region was observed.

\section{DISCUSSION}

The results show that the fine structures of spermatids and spermatozoa of Amblyomma hebraeum are similar in most respects to those of Amblyomma dissimili Koch, 1844 and Dermacentor andersoni Stiles, 1908 (Reger 1961, 1974) but that certain differences exist between these species.

The elongation process by which the $A$. hebraeum spermatid develops into a mature spermatozoon is like that described in argasid and ixodid ticks by Brinton et al. (1974), Borut \& Feldman-Muhsam (1976), and Wüest et al. (1978).

The groove observed by Reger (1961) in the $A$. dissimili spermatid is interpreted here as an anterior fold that expands, giving volume to this region once the evaginating anterior part of the spermatozoon is freed from the outer sheath. Suleiman \& Brown (1978) stated that the "groovelike depression" is absent in the anterior end of the spermatid of Dermacentor variabilis (Say); however, their fig. 11 of the nucleus and the groove shows this part to be in the anterior end.

Suleiman \& Brown (1978) mentioned a unique pluglike structure at the tip of the nucleate part of the spermatozoon. No pluglike structure was observed by us or in scanning views of this region by Feldman-Muhsam \& Filshie (1976) and Wüest et al. (1978).

We have demonstrated that the motile processes encircling the tip of the spermatozoon, observed by Casteel (1917) but contradicted by Oppermann (1935), are present in the $A$. hebraeum spermatid but concealed by the outer sheath. This view is in accord with the findings of Reger (1961) in A. dissimili.

Christophers (1906), Bonnet (1907), and Nordenskiöld (1920) misinterpreted the spermatid in the male vas deferens as the mature sperm. They did not envisage further developmental stages in the female genital tract. In Hyalomma "aegyptium (Linnaeus) 1758," Bonnet (1907) observed 2 forms of sperm, 1 rod shaped, the other filiform. These were obviously the spermatid before evagination and the mature spermatozoon, respectively.

Opinions differ regarding localization of mitochondria within the sperm body. In $A$. hebraeum, they are abundant in the anterior or clavate region, but few and randomly dispersed elsewhere and absent in the conical tip. According to Casteel (1917), who studied Argas miniatus Koch, 1844, and Sokolov (1958), who studied Ornithodoros tholozani (Laboulbene \& Mégnin) 1882 (=O. papillipes), mitochondria are arranged in rows or lines. Casteel (1917) observed that "the mitochondria are arranged in straight lines so that the front end of the tube appears longitudinally striated." The linear arrangement of mitochondria observed at the light microscopic level was recently confirmed on the ultrastructural level in $O$. moubata (Murray) 1877 (Breucker \& Horstmann 1968). Our results confirm that mitochondria accumulate in the anterior part; however, their specific arrangement in lines or rows was not observed in $A$. hebraeum. This is also concluded from the results of Oppermann (1935) and Reger (1961). The different results of Casteel (1917), Sokolov (1958), Breucker \& Horstmann (1968), and ourselves concerning mitochondrial distribution may be due to structural differences in individual species.

During the elongation process leading to the mature spermatozoon, an acrosomal canal forms by invagination of the cell membrane (=invagination membrane) and the underlying acrosome. The acrosomal canal was termed a "flagellum" by Oppermann (1935), Tuzet \& Millot (1937), Sharma (1944), Wagner-Jevseenko (1958), and Khalil (1969). These authors described an evagination process by which this "flagellum" protrudes outward from the nucleate end of the spermatozoon and the nucleus migrates into the "flagellum" base. This process occurs when the sperm leaves the seminal receptacle or in the oviducts (Khalil 1969). 
The seminal receptacle, oviducts, and ovaries of female $A$. hebraeum were examined before, during, and after ovulation, but this process was not observed. At no time were the sperm of this tick "flagellate." Evaginated "flagella" were said by Casteel (1917) to be nonfunctional and nonmotile and no axoneme was demonstrated. Thus, we refrain from calling this structure a "flagellum" and conclude that tick sperm are aflagellate cells.

The role of the acrosome in egg penetration has not been demonstrated. Therefore, we are uncertain of the true identity of this structure. The acrosome described here is similar to the acrosome identified by Breucker \& Horstmann (1968) in $O$. moubata and by Reger (1963) in A. dissimili.

\section{Motility}

All observers are in general agreement regarding the unusual type of tick sperm movement. The clavate mitochondrial part is anucleate but represents the active end, by which the spermatozoon moves forward, and is followed by the nucleate end.

Casteel (1917) observed that the anterior thick part of the sperm flattens at the terminal phase of maturation. He described movement at the tip of the anterior region as contracting and expanding. Recent observations on living tick sperm by Reger (1974) corroborate those of Christophers (1906), who described vermicular contortions of the anterior part of the sperm. Our observations on movement of this part showed that the tip moves in a peculiar rolling-up and folding-out manner and that the bulbous expansions are in continuous motion.

The general type of motility of tick spermatozoa was described by Christophers (1906) and Reger (1974) as a steady gliding movement and Sharma (1944) described it as rotary. Our observations on living sperm confirm the gliding movement and some rotary movement. A contractile system is probably involved in these movements, as suggested by Rothschild (1961), a view also accepted by Feldman-Muhsam \& Filshie (1976), who proposed that certain spermiophore movements may be explained by contraction of the cytoplasmic filaments. So-called "contractile elements" (Casteel 1917), "elastic strands" (Sokolov 1958), "filament bundles" (Breucker \& Horstmann 1968), and "subsurface filaments" (Reger 1963) have been observed in spermatozoa of different ticks. These elements, also observed in $A$. hebraeum, are termed "dense fibers." Microtubules are lacking in tick sperm cells but their function may be compensated for by the presence of dense fibers extending the entire length of these cells. The diameters of these fibers (100-150 $\AA$ ) correspond to the diameter of actin and myosin fibers, thus they may represent the above-mentioned contractile proteins frequently found in nonmuscle cells and thought to be involved in generating various "movements."

Apart from the dense-fibrillar elements, cellular processes or the fibrillar-granular region, or both, are probably involved in motion, as suggested by Reger (1974). The fringe of motile processes around the tip of the sperm head, which are in constant movement (Casteel 1917), may also contribute to motile activity.

The large accumulation of mitochondria and high concentration of $\beta$-glycogen particles among them are certainly related to energy production, which is essential for motility. The $\beta$-glycogen particles are considered to be an easily assimilable form of glucose storage. Glycogen presumably serves as an endogenous source of energy under aerobic conditions within the mitochondria.

Acknowledgments. We express our deepest gratitude to $\mathrm{Dr} \mathrm{H}$. Hoogstraal for critically reading the manuscript. We also wish to thank Professor H. Huggel, Head of the Laboratory of Comparative Anatomy and Physiology, for providing us with a working place in his laboratory and for help and encouragement. Thanks are also extended to $\mathrm{Mr}$ Bouvard of Les Barges Research Unit, Ciba-Geigy, for kindly supplying tick materials for this study. Sincere thanks are due to Madame Seif for technical assistance.

\section{LITERATURE CITED}

Bonnet, A. 1907. Sur les organes genitaux mâles et la spermatogenèse chez les Ixodes. C. R. Assoc. Fr. Av. Sci. 35: 54449.

Borut, S. \& B. Feldman-Muhsam. 1976. A new observation on spermateleosis in ticks. J. Parasitol. 62: 318-20.

Breucker, H. \& E. Horstmann. 1968. Die Spermatozoen der Zecke Ornithodorus moubata (Murr.). Z. Zellforsch. Mikrosk. Anat. 88: 1-22.

1972. Die Spermatogenese der Zecke Ornithodoros moubata (Murr.). Z. Zellforsch. Mikrosk. Anat. 123: 18-46.

Brinton, L. P., W. Burgdorfer \& J. H. Oliver, Jr. 1974. Histology and fine structure of spermatozoa and egg passing in the female tract of Dermacentor andersoni Stiles (Acari: Ixodidae). Tissue E Cell 6: 109-25.

Casteel, D. B. 1917. Cytoplasmic inclusions in male germ cells of the fowl tick. J. Morphol. 28: 643-93.

Christophers, S. R. 1906. The anatomy and histology of ticks. Sci. Mem. Off. Med. Sanit. Dep. Gov. India, n.s. No. 23. 55 p.

El Said, A. \& Z. Swiderski. 1980a. Regional specialization of the sperm membrane in the tick Amblyomma hebraeum Koch (Acari: Ixodidae). Cell Tissue Res. 208: 35-45.

$1980 \mathrm{~b}$. A freeze etching study on the origin of cellular processes in spermatids of the tick Amblyomma hebraeum Koch (Acari: Ixodidae). Proc. 7th Europ. Congr. Electr. Microsc. The Hague, 1980. 2: 60-61. 
1980c. Comparative freeze-etch replica and thin section studies on the phagocytotic process in the sperm of the tick Amblyomma hebraeum (Acari: Ixodidae). Proc. 7th Europ. Congr. Electr. Microsc. The Hague, 1980. 2: 62-63.

Feldman-Muhsam, B. \&c B. K. Filshie. 1974. The ultrastructure of the connecting links between tick spermiophores and their symbionts. Abstr. Proc. 3rd. Int. Congr. Parasitol., Munich, 1974. 2: 965-66.

1976. Scanning and transmission electron microscopy of the spermiophores of Ornithodoros ticks: an attempt to explain their motility. Tissue E Cell 8: 411-19.

1979. A SEM study of spermiophores of Ornithodoros ticks. p. 681-85. In: Proc. 4th. Int. Congr. Acarol. Saalfelden, 1974.

Feldman-Muhsam, B., B. K. Filshie \& S. Borut. 1975. EM study on tick prospermium relevant to onset of spermateleosis. Abstr. 50th Annu. Meet. Am. Soc. Parasitol., Louisiana. p. 49.

Khalil, G. M. 1969. Biochemical and physiological studies of certain ticks (Ixodoidea). Gonad development and gametogenesis in Argas (Persicargas) arboreus, Kaiser, Hoogstraal and Kohls (Argasidae). J. Parasitol. 55: 1278-97.

1970. Biochemical and physiological studies of certain ticks (Ixodoidea). Gonad development and gametogenesis in Hyalomma (H.) anatolicum excavatum Koch (Ixodidae). $J$. Parasitol. 56: 596-610.

Nordenskiöld, N. A. E. 1920. Spermatogenesis in Ixodes ricinus L. Parasitology 12: 159-65.

Oppermann, E. 1935. Die Entstehung des Riesenspermien von Argas columbarum (Shaw) (reflexus F.). Z. Mikrosk. Anat. Forsch. 37: 538-60.

Reger, J. F. 1961. The fine structure of spermatids from the tick Amblyomma dissimili. J. Ultrastruct. Res. 5: 584-99.

1962. A fine-structure study on spermiogenesis in the tick Amblyomma dissimili with special reference to the development of motile processes. J. Ultrastruct. Res. 7: 550-65.
1963. Spermiogenesis in the tick Amblyomma dissimili as revealed by electron microscopy. J. Ultrastruct. Res. 8: 60721.

1974. The origin and fine structure of cellular processes in spermatozoa of the tick Dermacentor andersoni. J. Ultrastruct. Res. 48: 420-34.

Rothschild, Lord. 1961. Structure and movement of tick spermatozoa (Arachnida, Acari). Q. J. Microsc. Sci. 102: 23947.

Samson, K. 1909. Zur Spermiohistiogenese der Zecken. Sitzungsber. Ges. Naturf. Fr. Berlin No. 8: 486-99.

Sharma, G. P. 1944. Studies on spermatogenesis in ticks. Proc. Natl. Inst. Sci. India 10: 305-16.

Sokolov, I. I. 1958. Cytological studies of the development of male germ cells in Ornithodoros papillipes Bir. (Acari, Ixodoidea). Entomol. Obozr. 37: 260-81. (In Russian.)

Suleiman, A. S. \& G. G. Brown. 1978. Spermiogenesis in the dog tick Dermacentor variabilis (Say). Iowa State J. Res. 53: 93-108.

Thiery, J. P. 1967. Mise en évidence des polysaccarides sur coupes fines au microscope électronique. J. Microsc. Paris 6: $987-1118$.

Till, W. M. 1961. A contribution to the anatomy and histology of the brown ear-tick Rhipicephalus appendiculatus Newmann. Mem. Entomol. Soc. South. Afr. 6: 5-124.

Tuzet, O. \& J. Millot. 1937. Recherches sur la spermiogenèse des Ixodes. Bull. Biol. Fr. Belg. 71: 190-205.

Wagner-Jevseenko, O. 1958. Fortpflanzung bei Ormithodorus moubata und genitale Übertragung von Borrelia duttoni. Acta Trop. 15: 118-68.

Warren, E. 1933. On atypical modes of sperm development in certain arachnids. Ann. Natal Mus. 7: 151-94.

Wüest, J., A. El Said, Z. Swiderski \& A. Aeschlimann. 1978. Morphology of the spermatid and spermatozoon of $\mathrm{Am}$ blyomma hebraeum Koch (Acarina: Ixodidae). Z. Parasitenkd. 55: 91-99.

\section{NOTICE}

\section{FORUM ON PACIFIC SYSTEMATICS COLLECTIONS AND BIOGEOGRAPHY SYMPOSIUM}

At the annual meetings of the Association of Systematics Collections, to be held 23-26 May 1982, at the Bishop Museum, Honolulu, two symposia will be held. The first symposium will be a one-day forum on the status, care and use of collections of Pacific area biota. This forum will relate primarily to collections housed on Pacific islands, but will also involve Pacific collections in museums elsewhere. Matters of location and extent of collections, their curation, availability, safe-keeping and future will be discussed. Speakers will address present situations in certain island nations or nearby countries and will speak on curatorial, legal, service and other aspects of collections. A second, one-day symposium will deal with Pacific island biogeography relating to insects, other animals and plants, mostly terrestrial but also marine. Emphasis will be on tropical Pacific island groups.

Everyone is welcome to come to these symposia and to participate in the discussions, as well as the regular meetings of the Association. For further information, please write: Forum, \% Dr J. L. Gressitt or Dr F. J. Radovsky, Bishop Museum, P.O. Box 19000-A, Honolulu, Hawaii 96819. 